\title{
Layer size effect on the shock compression behavior of fcc-bcc
}

\section{nanolaminates}

\author{
R. F. Zhang, ${ }^{1,2,}$, T. C. Germann, ${ }^{1, *}$ X.-Y. Liu ${ }^{3}$, J. Wang ${ }^{3}$, and I. J. Beyerlein ${ }^{1}$ \\ ${ }^{1}$ Theoretical Division, Los Alamos National Laboratory, Los Alamos, NM, 87545, USA \\ ${ }^{2}$ School of Materials Science and Engineering and International Research Institute for \\ Multidisciplinary Science, Beihang University, Beijing 100191, P. R. China \\ ${ }^{3}$ Materials Science and Technology Division, Los Alamos National Laboratory, Los Alamos, \\ NM, 87545, USA
}

\begin{abstract}
Using large scale nonequilibrium molecular dynamics simulations, we study the role of interfaces and layer thickness in the response of the experimentally observed $\mathrm{Cu} / \mathrm{Nb}$ nanolayered composites to shock compression. We observe a critical layer thickness $(<20$ $\mathrm{nm}$ ) below which lattice dislocations nucleate preferentially from the $\mathrm{Cu} / \mathrm{Nb}$ interfaces. Within this regime of interface dominance, samples with a layer thickness of $5 \mathrm{~nm}$ have the largest Hugoniot elastic limit (the critical shock pressure required for dislocation production), which then decreases for finer layer thicknesses, where dislocation transmission across the interfaces becomes more frequent. The dislocation slip systems emitted and transmitted across the interfaces are strongly linked to interface structure and crystallography. The strong layer thickness and interface structure effects found here can provide insight into designing shock-resistant nanolayered composites.
\end{abstract}

Keywords: MD simulation, nanocomposites, interface, dislocation, shock compression *Corresponding authors: zrf@buaa.edu.cn, tcg@lanl.gov 


\section{Introduction}

Materials for next generation applications are expected to push the envelope and exhibit predictable lifetime performance in extreme environments for longer service-lives than are attainable with today's materials. To this end, nanolayered composite metals have become an attractive candidate. Many experimental studies have shown that nanolayered metals exhibit extraordinary resiliency in extreme environments, such as high temperatures, radiation, stresses, and large strains, above and beyond that possible with their constituents alone [1] [2] [3] [4] [5]. These nanomaterials combine two or more dissimilar metals and contain an unusually high density of bimetal interfaces [5] [6] [7]. Recently, small-scale studies have been focused on the atomic structures of these bimetal interfaces and how they influence basic deformation processes, like dislocation nucleation and deformation twinning [8] [9]. From both experiment and simulation, it was found that these mechanisms were very sensitive to the structure of the interfaces at an atomic scale [5] [10] [11].

In order to determine how interface structure would contribute to composite response in an extreme environment, large scale nonequilibirum molecular dynamics (MD) simulations were carried out to investigate the effect of interface structure on shock compression response [12]. A three-dimensional model of single crystal multilayers was constructed with either a $\{112\}$ fcc $\|\{112\}$ bcc interface or a $\{111\}$ fcc $\|\{110\}$ bcc interface, both adopting a KurdjumovSachs (KS) orientation relation. It was found that the pressure to initiate plasticity was twice as high in the $\{111\} \mathrm{fcc} \|\{110\}$ bcc KS nanocomposite than the $\{112\} \mathrm{fcc} \|\{112\}$ bcc KS nanocomposite [12]. The difference was attributed to differences in the stresses required to nucleate and transmit dislocations across the interface. This result implies that atomic structure plays a key role in interface-driven plasticity.

A question that remains concerns layer size effects on high-rate deformation plasticity. It has been demonstrated in several experimental studies that layer size significantly impacts the hardness and strength of multilayers [13] [1]. It has been shown in a recent experimental 
study that nanocrystal size greatly affects the propensity for nanomaterials to deformation twin [14]. Based on dislocation theory, it has been proposed that layer thickness has a profound effect on the plastic deformation mechanism, from confined layer slip to interface crossing [13]. Both experimental and simulation studies have observed a cross-over from full dislocation-mediated to partial-dislocation mediated slip as the crystal size reduces below a critical value [15] [16] [17] [18]. In FCC metals, the effect of grain size on dislocations generated from grain boundaries were analyzed using MD simulation by Asaro et al. [19] and Traiviratana et al. [20]. Using phase-field dislocation dynamics, nanograin sizes have also been found to influence the size of the stacking faults that are emitted from grain boundaries [21]. Many of these size effects arise because of changes in where dislocations nucleate and whether they can transmit across the interfaces.

In this work, we apply large scale nonequlibrium $\mathrm{MD}$ simulations to $\mathrm{Cu}-\mathrm{Nb}$ nanolayers as a prototype for examining the effect of layer size on the interface-mediated processes during shock compression. To this end, we first construct a new $\mathrm{Cu}-\mathrm{Nb}$ interatomic potential for $\mathrm{Cu}$ and $\mathrm{Nb}$ potentials proven to provide accurate defect dynamics under high pressure. We show that there are two important length scales affecting shock compression behavior, one below which interface-mediated dislocation nucleation dominates, and another below which dislocation transmission becomes more frequent. The latter gives rise to a peak Hugoniot elastic limit (critical shock pressure) for a $5 \mathrm{~nm}$ layer thickness.

\section{Strategy and Methodology}

\section{A. Construction of $\mathrm{Cu}-\mathrm{Nb}$ cross potential}

Some interatomic potentials for bcc metals, such as $\mathrm{Nb}$, can exhibit artificial structural phase transformations under high pressure, making them unsuitable for shock compression studies [22] [23]. In prior work, we have shown that the origin can be traced to artificial minima in the material gamma surfaces under extreme pressures [23]. After comparing different potentials developed for $\mathrm{Nb}$, we found that the one developed by Ackland and 
Thetford best describes the high-pressure response, providing a good description of $\mathrm{Nb}$ deformation twinning and other defect-related properties. Therefore, here we adopt the embedded atom method (EAM) potential developed by Voter and Chen [24] for fcc $\mathrm{Cu}$, and the Finnis-Sinclair (FS) potential by Ackland and Thetford [25] for bcc Nb. Development of the cross potential between $\mathrm{Cu}$ and $\mathrm{Nb}$ is accomplished by the following procedure.

We employ the same fitting scheme as proposed by Demkowicz et al. [26] but use Ackland FS Nb potential in place of the Johnson EAM Nb potential [26]. The interaction between $\mathrm{Cu}$ and $\mathrm{Nb}$ is described by a two-body Morse potential,

$$
C u N b(r)=D_{M}\left(1 \quad e^{{ }^{(}\left(r R_{M}\right)}\right)^{2} \quad D_{M},
$$

where $r$ is the interatomic distance, and $D_{M}, a_{M}$ and $R_{M}$ are three fitting constants. In addition, two transformation invariants were taken into consideration,

$$
F^{\text {new }}(\overline{ })=F\left({ }^{-}\right)+g^{-}, \quad{ }^{n e w}(r)=(r) \quad 2 g(r)
$$

and

$$
{ }^{\text {new }}(r)=s(r), F^{\text {new }}(-)=F(-/ s),
$$

which adds three more fitting constants, $g_{C u}, g_{N b}$, and $s_{N b}$.

Due to the immiscibility of $\mathrm{Cu} / \mathrm{Nb}$, there are no equilibrium compounds that can be used for fitting the cross potential. To overcome this, first-principles calculations are first performed to obtain some fundamental properties of the $\mathrm{B} 1(\mathrm{NaCl})$ and $\mathrm{B} 2(\mathrm{CsCl})$ structures, e.g., lattice parameters, formation enthalpies and elastic constants. These were then used in the fitting procedure. Table I lists the fitted and reproduced properties of the newly constructed cross potential for the $\mathrm{Cu} / \mathrm{Nb}$ system. The latter are found to compare well with both experimental values and $a b$ initio density functional theory (DFT) values for the lattice parameters, cohesive energies and elastic constants of the pure metals and some selected compounds [27] [28] [29]. As will be shown in the next section, the new cross-potential 
provides estimates of interfacial energy and structure in agreement with those of previous $\mathrm{Cu} / \mathrm{Nb}$ potentials [26].

\section{B. MD modeling and simulation}

In the present study, we consider $\mathrm{Cu} / \mathrm{Nb}$ interfaces, which have the crystallographic character commonly observed in physical vapor deposited foils [30] [31]. Our models are created by joining a $\{111\}$ slab of perfect fcc $\mathrm{Cu}$ with a $\{110\}$ slab of perfect bcc $\mathrm{Nb}$ in a KS orientation relationship, meaning the planes $(111) \mathrm{Cu} / /(110) \mathrm{Nb}$ are aligned, as are the [1$10] \mathrm{Cu} / /[-111] \mathrm{Nb}$ and $[11-2] \mathrm{Cu} / /[1-12] \mathrm{Nb}$ axis pairs in the plane of the interface. The $\mathrm{x}-\mathrm{axis}$ is along the $[11-2] \mathrm{Cu}$ direction, the $\mathrm{y}$-axis is along the $[1-10] \mathrm{Cu}$ direction, and the $\mathrm{z}$-axis is along the $[111] \mathrm{Cu}$ direction. The interface planes are then parallel to the $\mathrm{x}-\mathrm{y}$ plane. The multilayer interface models terminate at the free surfaces at both sides of the model. Periodic boundary conditions are applied in the $x$ and $y$ directions, whose dimensions are chosen such that the absolute strains imposed on $\mathrm{Cu}$ and $\mathrm{Nb}$ semi-infinite perfect crystals are minimized [32] [33]. Four types of $\mathrm{Cu} / \mathrm{Nb}$ multilayer models with different layer thickness $(2.5 \mathrm{~nm}, 5$ $\mathrm{nm}, 10 \mathrm{~nm}$ and $20 \mathrm{~nm}$ ) are constructed to study the effect of layer thickness on the formation of defective structure. For each layer thickness, the total sample length in the shock direction is about $120 \mathrm{~nm}$, giving total sample sizes ranging from about 3 to 4 million atoms. This initial multilayer model is first relaxed by a quenching MD method combined with a conjugate gradient algorithm. Afterwards, an Isothermal-Isobaric (NPT) ensemble is applied to equilibrate the sample at zero pressure and the desired $300 \mathrm{~K}$ target temperature. After these procedures, the relaxed multilayered models are used for the shock compression and release studies using the Scalable Parallel Short-range Molecular dynamics code (SPaSM) [34] [35] [36].

A shock wave is then introduced by impacting the sample at the specified piston (or particle) velocity $u_{p}$ against a stationary specularly reflecting wall, i.e., the so-called momentum mirror method which has been used to study the homogenous nucleation of 
dislocations [36] [37], twins [38], and phase transformations [39] in defect-free single crystals. No additional coupling of the atoms to a heat bath is done, since shock waves are assumed to be adiabatic i.e., occuring too fast for any heat exchange with the environment [40] [39]. The piston velocity $u_{p}$ is varied to find a rough critical threshold at which the defective structure first appears in the samples, i.e. the Hugoniot elastic limit. Because there are no pre-existing (threading) defects within the layers, the critical pressure corresponds to that needed to nucleate fresh dislocations either within the layers or from the interfaces, under the uniaxial strain state created by the initial elastic shock compression.

For better on-the-fly visualization, the centro-symmetry factor (CSF) is used to identify defects during the course of shock propagation using the MD_RENDER code [41]. The CSF parameter is a quantitative measure of the deviation from the ideal centro-symmetry in the atom's neighborhood. It can be defined as [42] $P={ }_{i=1}^{N_{p}}\left|r_{i}+r_{i+N_{p}}\right|^{2}$, where $\mathbf{r}_{i}$ and $\mathbf{r}_{i}+N_{p}$ are positions of the $i$ th pair of neighbors relative to the atom under consideration. In this summation, the number of nearest-neighbor pairs $N_{p}$ depends on the host crystal structure: $N_{p}$ is 6 for FCC and 4 for BCC. For perfect FCC (or BCC) structures, vectors $\mathbf{r}_{i}$ and $\mathbf{r}_{i}+N_{p}$ in each neighbor pair cancel each other so that $P$ vanishes for every atom. To distinguish Shockley partial dislocations in an fcc crystal, we also use common neighbor analysis (CNA).

\section{Results and Discussions}

\section{A. Interface structure}

Fig. 1 (a)-(b) shows the relaxed atomic $\mathrm{Cu} / \mathrm{Nb}$ interface structure that is obtained by relaxing a bi-crystal using the newly constructed $\mathrm{Cu} / \mathrm{Nb}$ potentials. Besides the quantitative difference in interface formation energy, $669 \mathrm{~mJ} / \mathrm{m}^{2}$ using the newly constructed $\mathrm{Cu} / \mathrm{Nb}$ potentials and $569 \mathrm{~mJ} / \mathrm{m}^{2}$ [43] using the cross-pair potential by Demkowicz et al. [26], we obtained the same interface structure as reported previously by our team [44] [32]. $\mathrm{Cu}$ and $\mathrm{Nb}$ form a sharp interface without intermixing. The atoms marked by magenta and red colors 
indicate misfit dislocation intersections (MDIs). These MDIs coincide with the points where the two separate intrinsic dislocation arrays intersect [45]. As indicated by the parallelogram in Fig. 1b, the MDIs exhibit a quasi-repeatable pattern of a two-dimensional boundary unit cell (BUC). Using interface defect analyses, two sets of misfit dislocation arrays have been identified, as indicated by the dashed lines in Fig. 1a [33] [11] [46]. The line orientations and Burgers vectors for these misfits have been characterized in [33]. The first dislocation array has line sense $\xi_{1}=\left(\cos 28^{\circ}, \sin 28^{\circ}\right)$, a spacing of $21.3 \AA$, and a Burgers vector of $(0,2.70) \AA$. The second array has line sense $\xi_{2}=\left(\cos 90^{\circ}\right.$, sin $\left.90^{\circ}\right)$, a spacing of $12.45 \AA$, and a Burgers vector of $(-2.45,1.56) \AA$.

Recently, it was shown that this misfit dislocation network plays a key role in the nucleation of dislocations from the interface under quasistatic mechanical loading [9] [11] [47]. Dislocation loops are emitted along the crystallographic slip planes that intersect the interface plane along the misfit dislocation lines, but do not form on planes that do not satisfy this criterion despite being equally stressed. On this basis, for later reference, we illustrate some geometric relationships between this misfit dislocation network and the dislocation glide planes in $\mathrm{Cu}$ and $\mathrm{Nb}$. Fig. 1c shows the unfolded tetrahedron of slip systems out of the interface on the $\mathrm{Cu}$ side, in which the three fcc glide planes are marked by $\mathrm{BCD}, \mathrm{ACD}, \mathrm{ABD}$ planes, and the plane $\mathrm{ABC}$ corresponds to the $\mathrm{Cu} / \mathrm{Nb}$ interface plane. Likewise, the $2 \mathrm{D}$ representation of an unfolded polyhedron of the relevant slip systems out of the interface on the $\mathrm{Nb}$ side is shown in Fig. 1d, in which the five bec glide planes are indicated by B'C'F', $A^{\prime} C^{\prime} G, A^{\prime} C^{\prime} G^{\prime}, A^{\prime} B^{\prime} E, A^{\prime} B^{\prime} E^{\prime}$ planes, and the plane $A^{\prime} B^{\prime} C^{\prime}$ corresponds to the $\mathrm{Cu} / \mathrm{Nb}$ interface plane. The dislocation line $\xi_{1}$ is nearly parallel to the $\mathrm{AC}$ trace of glide plane $\mathrm{ACD}$ in the $\mathrm{Cu}$ side, but slightly deviates from the $A^{\prime} C^{\prime}$ trace of glide planes $A^{\prime} C^{\prime} G$ and $A^{\prime} C^{\prime} G$ '. Meanwhile, the dislocation line $\xi_{2}$ is exactly parallel to the $\mathrm{AB}$ trace of glide plane ABD on the $\mathrm{Cu}$ side, and the A'B' trace of glide plane A'B'E (or A'B'E') on the $\mathrm{Nb}$ side. According to the theory in [9] [11], these planes are candidates for dislocation nucleation, whereas the 
others are not. We will further observe here that these geometric orientation relationships between the adjoining crystals and their common interface also greatly impact dislocation nucleation as well as dislocation transmission across the interface during shock compression.

\section{B. Dislocation nucleation at interface}

Interfaces are expected to dominant plastic deformation as the interface spacing $h$ decreases, or the interface density increases. Such critical length scales are often associated with reduced defect content and suppression of pile-ups within the layers or enhanced stress states that are generated as crystalline sizes shrink to very fine scales (e.g., $<10 \mathrm{~nm}$ ). We first explore the effect of interface spacing $h$ (or layer thickness) on where plasticity initiates in an otherwise pristine composite. Two critical length scales are observed.

The first is the length scale between $h=10 \mathrm{~nm}$ and $20 \mathrm{~nm}$, where dislocation nucleation transitions from occurring within the layers to at the interfaces. As shown in Fig. 2 (a)-(c), it is observed that fcc Shockley partial dislocation loops are emitted from the $\mathrm{Cu} / \mathrm{Nb}$ interface into $\mathrm{Cu}$ for the $\mathrm{Cu} 2.5 / \mathrm{Nb} 2.5 \mathrm{~nm}, \mathrm{Cu} 5 \mathrm{~nm} / \mathrm{Nb} 5 \mathrm{~nm}$ and $\mathrm{Cu} 10 \mathrm{~nm} / \mathrm{Nb} 10 \mathrm{~nm}$ models at critical piston speeds of $u_{p}=625,650$ and $625 \mathrm{~m} / \mathrm{s}$, respectively. Nucleation into $\mathrm{Cu}$ from the interface is preferred over $\mathrm{Nb}$ since $\mathrm{Cu}$ dislocations have the smaller Burgers vector and selfenergy [48]. In contrast, for the thicker $\mathrm{Cu} 20 \mathrm{~nm} / \mathrm{Nb} 20 \mathrm{~nm}$ model and for comparison, a bulk $\mathrm{Nb}$ crystal, a dislocation loop first appears inside the $\mathrm{Nb}$ layer at $u_{p}=615 \mathrm{~m} / \mathrm{s}$ and $600 \mathrm{~m} / \mathrm{s}$, respectively. Fig. 2(d) and (e) shows the initial stage of this homogeneous dislocation nucleation within one $\mathrm{Nb}$ layer.

To see how this size effect manifests later in deformation, Fig. 3 shows snapshots of the (a) $2.5 \mathrm{~nm}$, (b) $5 \mathrm{~nm}$, (c) $10 \mathrm{~nm}$, and (d) $20 \mathrm{~nm}$ multilayers at the time of $19.5 \mathrm{ps}$, near the end of the shock compression stage. For all layer thicknesses, the sample is travelling at a particle velocity $u_{p}=650 \mathrm{~m} / \mathrm{s}$. Shockley partials are largely responsible for plastic deformation in the $\mathrm{Cu}$ layers for all thicknesses. In the $\mathrm{Nb}$ layers, twins and slip dislocations can be identified for 
thicker layered composite $20 \mathrm{~nm}$ (see Fig. 3c and 3d), and only slip dislocations in all the remaining finer layers.

The second important size effect corresponds to the layer thicknesses of $5 \mathrm{~nm}$, where the threshold for interface-driven plasticity achieves a peak value. This critical value for the onset of plastic yield involves the motion of the first set of dislocations formed, including their nucleation, propagation, and transmission of dislocations across interfaces. A similar size effect in strength is seen in hardness testing of these $\mathrm{Cu}-\mathrm{Nb}$ multilayers via roomtemperature and high-temperature nano-indentation, also applied normal to the interfaces [49] [13] [1] [50]. There, a peak hardness is achieved also at $h \sim 5 \mathrm{~nm}$ and is presumed to correspond to the length scale at which interface crossing prevails.

For the case of the $5 \mathrm{~nm}$ composite, Fig. 4a shows a snapshot of dislocation nucleation from the interface into the $\mathrm{Cu}$ crystal at an incipent stage at $6.5 \mathrm{ps}$. To expose the relatinship with the interface misfit dislocation network, Fig. $4 \mathrm{~b}$ shows the top view of this nucleation event from the $\mathrm{Cu}$ side, where the dashed orange lines indicate a few misfit dislocation lines. For this particular loading state, three Shockley partial dislocations that can form an intrinsic stacking fault as it propagates away from the interface have the same Schmid factor. With the passage of shock compression wave, however, only one partial dislocation loop expands, as seen in Fig. 4c and 4d, while the other two appear to be hindered. The preferred partial dislocation loop nucleates along the misfit dislocation line $\xi_{1}$, which is nearly aligned with the trace of glide plane of ACD at interface (Fig. 1a,c). As mentioned, the preference for dislocations to nucleate along misfit dislocation lines was reported previously in other MD simulations in uniform loading [48] and has been predicted by a geometric based model [11]. The prevalence of this nucleation mechanism among simulations carried out at different strain rates and temperatures highlights the strong relationship between the intrinsic misfit dislocation network and interface driven plasticity. 
Last, we note that with continued shock propagation, the trailing Shockley partial dislocation is emitted from the interface (Fig. 4c). The leading and trailing partials form an extended full dislocation that is mobile in the $\mathrm{Cu}$ crystal.

\section{Dislocation transmission at interface}

After dislocations nucleate, they expand and reach the neighboring interfaces where they either are aborbed or transmit across the interfaces. The transmission of dislocations across this particular interface has been shown to be difficult [32]. Atomic-scale simulations have found that the core of the absorbed dislocation tends to spread in the plane of the interface, which greatly hinders its re-emission into the adjoining crystals, which would complete the transmission process. Another factor that influences transmissibility is the degree of alignment of the slip planes and Burgers vectors that make up the transmission pathway of the dislocation [51] [8]. Whether two slip systems across an interface are sufficiently well aligned for dislocation transmission has been measured by a geometry factor. This factor, designated as m', can be calculated from two angles: the angle $\varphi$, between the slip directions $\mathrm{b}$ and $\mathrm{b}^{\prime}$ and the angle $\lambda$, between the normals $\mathrm{n}$ and n' to the slip planes (see Fig. 5). The geometric compatibility factor $\mathrm{m}^{\prime}$, is calculated as $\mathrm{m}^{\prime}=(\cos \varphi)(\cos \lambda)$, which varies from 0 to 1, with 1 being a perfectly aligned transmission path.

Fig. 6a shows the relative orientation of the FCC and BCC active slip systems with respect to the $\mathrm{Cu} / \mathrm{Nb} \mathrm{KS}$ interface. Fig. $6 \mathrm{~b}$ gives the top view of the interface together with the traces of active glide planes on the interface: black $A B C^{\prime}$ is for the $\mathrm{Nb}$ side and pink $\mathrm{ABC}$ for $\mathrm{Cu}$. Only one set of $\{111\} \mathrm{Cu}$ and $\{110\} \mathrm{Nb}$ glide planes share a common trace of $\mathrm{AB}(<1$ $10>$ ) at the interface. The compatibility factor m' for transmission to and from the ACD glide plane in $\mathrm{Cu}$ and the glide $\mathrm{A}^{\prime} \mathrm{C}^{\prime} \mathrm{G}^{\prime}$ plane in $\mathrm{Nb}$ is calculated to be 0.66 , which is much larger than the other possible transimission paths to $A^{\prime} C^{\prime} G\left(m^{\prime}=0.056\right), B^{\prime} C^{\prime} F^{\prime}\left(m^{\prime}=0.035\right.$ and $0.27), A^{\prime} B ' E\left(m^{\prime}=0.392\right)$, and A'B'E' $\left(m^{\prime}=0.021\right)$. 
Fig. 7a shows a dislocation transmission event from the $\mathrm{Cu}$ side of an interface into the $\mathrm{Nb}$ side. In this figure, the sample is travelling upwards at a particle velocity $u_{p}=650 \mathrm{~m} / \mathrm{s}$ towards a stationary piston at the top, and the resulting shockwave travels downward. The $\mathrm{Cu}$ and $\mathrm{Nb}$ slip systems involved correspond to those with the highest m': ACD (on the Cu side) and $\mathrm{A}^{\prime} \mathrm{C}^{\prime} \mathrm{G}^{\prime}$ (on the $\mathrm{Nb}$ side) (refer to Fig. 1c and $1 \mathrm{~d}$ for slip systems).

In a similar manner, the dislocation in $\mathrm{Nb}$ has propagated to the opposing interface and has transmitted into $\mathrm{Cu}$. Again, the transmission pathway corresponds to the one with the highest compatibility factor m', i.e., from an active glide plane of $\mathrm{A}^{\prime} \mathrm{C}^{\prime} \mathrm{G}^{\prime}$ in the $\mathrm{Nb}$ layer onto the ACD glide plane in the $\mathrm{Cu}$ layer.

At the transmission site, a residual dislocation is left behind within the interface. Fig. 8 shows an example of the local disruption of the interface atomic structure after a single transmission event. As plastic deformation develops in the layers (Fig. 4), slip transmission appears to become less frequent. Transmission can become increasingly more difficult for many reasons: accumulated changes in interface structure (e.g., Fig. 8), backstresses by extrinsic dislocations stored in the interface [52], and changes in interface character and hence m' as either crystal reorients during deformation.

\section{Dislocation absorption and annihilation at interface}

Finally we examine the evolution of the shock-induced defects during the shock release to gain some clues on interface-mediated recovery. It may be expected that when the shock wave reaches the free surface and a rarefaction (relief) wave is produced, the stacking faults that were produced in shock compression could be mostly annihilated. This idea is consistent with the observation of much smaller dislocation densities in recovered shocked materials [53]. Although quantitative comparison of dislocation density between those predicted in MD simulations and experiments is still far beyond expectation, some qualitative trends may be considered intuitively useful. For instance, previously shock simulations of single crystals without initial defects have been carried out [54]. When comparing the calculated density of 
defects with post-mortem observations on recovered single crystal $\mathrm{Cu}$, it was found that the dislocation densities in the simulations were several orders of magnitude lower [53]. Three reasons were suggested by Cao et al. [53] for the discrepancy: (a) the higher stain rate and much shorter rise time in the MD simulations, (b) the small volume of the model single crystal, and (c) the possibility that most defects are annealed out in the simulations.

The present MD simulations on nanolayered samples are found not to follow exactly the same trend as those performed on the single crystals due to the presence of interfaces. To examine defect evolution, Fig. 9 shows the change in the atomic percentage of central symmetry factor (CSF) greater than unity (corresponding to defects) for the $\mathrm{Cu} 5 \mathrm{~nm} / \mathrm{Nb} 5 \mathrm{~nm}$ multilayer model. It can be clearly seen that the peak defect density is reduced by $\sim 30 \%$ during the initial shock release stage, with only a negligible further decrease during the subsequent annealing process. We observe that most of the defect substructures inside $\mathrm{Nb}$ are recovered during the shock relief process, while the substructure inside the fcc-Cu layers is only partially recovered during shock release of the multilayered $\mathrm{Cu}-\mathrm{Nb}$ nanocomposites. At the same time, we find that the originally planar interfaces have been significantly altered by the numerous dislocation-interface interactions (primarily emission and transmission) during shock compression. This change in interface structure may be one reason why the shockinduced defects are not fully recovered. This result may shed light on why it has been reported that voids initiate in the $\mathrm{Cu}$ phase rather than the $\mathrm{Nb}$ phase during shock testing of these nanolayers [55].

\section{Conclusions}

In this work, we used atomic scale MD simulations to study the response of $\mathrm{Cu} / \mathrm{Nb}$ nanolayered composites to shock compression. Construction of a reliable MD model for this extreme pressure environment required development of a $\mathrm{Cu}-\mathrm{Nb}$ cross potential derived using the Voter-Chen $\mathrm{Cu}$ and Ackland $\mathrm{Nb}$ potentials. The energy and atomic structure of the $\mathrm{KS}$ 
$\mathrm{Cu} / \mathrm{Nb}$ interfaces with the new cross-potential are shown to be in agreement with those reported previously. The main conclusions of this work are as follows:

- Under shock compression, we reveal a critical layer thickness $(<20 \mathrm{~nm})$ below which lattice dislocations nucleate preferentially from the $\mathrm{Cu} / \mathrm{Nb} \mathrm{KS}$ interfaces.

- A peak in the Hugoniot elastic limit (resistance to shock-induced plasticity) is found for a layer thickness of $5 \mathrm{~nm}$, below which dislocation transmission across the interface becomes more frequent.

- The preferred transmission pathways to and from $\mathrm{Cu}$ and $\mathrm{Nb}$ crystals abide by the simple geometric factor that measures the degree of alignment of slip systems across an interface.

- Most of the dislocation substructures formed within the layers during shock compression are recovered in $\mathrm{Nb}$ but not in $\mathrm{Cu}$, which we suspect is a result of a change in the interface morphology and defect content during shock compression.

Acknowlegements: RFZ would like to acknowledge support by a Los Alamos National Laboratory Director's Postdoctoral Fellowship, the Zhuo-Yue Talents Plan of Beihang University and National Thousand Young Talents Program of China. TCG, JW, and IJB were supported by the Center for Materials at Irradiation and Mechanical Extremes, an Energy Frontier Research Center funded by the U.S. Department of Energy, Office of Science, Office of Basic Energy Sciences under Award Number 2008LANL1026. XYL would like to acknowlege support by Los Alamos National Laboratory Directed Research and Development program. We thank A. Misra, R. Hoagland, M. I. Baskes, W. A. Nix, and J. P. Hirth for valuable discussions. We also thank G. J. Ackland for providing the Nb potentials. 


\section{References}

[1] Monclus MA, Zheng SJ, Mayeur JR, Beyerlein IJ, Mara NA, Polcar T, Llorca J, MolinaAldareguia JM. Appl Phys Lett Mater 2013;1:052103.

[2] Zheng SJ, Carpenter JS, McCabe RJ, Mara NA. Sci Rep 2014;4:4226.

[3] Beyerlein IJ, Caro JA, Demkowicz MJ, Mara NA, Misra A, Uberuaga BP. Materials Today 2013;16:443.

[4] Han WZ, Demkowicz MJ, Mara NA, Fu E, Sinha S, Rollett AD, Wang Y, Carpenter JS, Beyerlein IJ, Misra A. Adv Mater 2013;25:6975.

[5] Mara NA, Beyerlein IJ. "Review: effect of bimetal interface structure on the mechanical behavior of $\mathrm{Cu}-\mathrm{Nb}$ fcc-bcc nanolayered composites", J Mater Sci 2014, In press. DOI: 10.1007/s10853-014-8342-9.

[6] Misra A. Mechanical Behavior of Metallic Nanolaminates in Nanostructure Control of Materials, edited by A.J. Hill \& R.H.J. Hannink (Woodhead Publishing Co., UK, 2006), pp. 146-176.

[7] Beyerlein IJ, Mayeur JR, McCabe RJ, Zheng SJ, Carpenter JS, Mara NA. Acta Mater $2014 ; 72: 137$.

[8] Beyerlein IJ, Wang J, Kang K, Zheng SJ, Mara NA. Mater Res Lett 2013;1:89.

[9] Beyerlein IJ, Wang J, Zhang RF. Appl Phys Lett Mater 2013;1: 032112.

[10] Beyerlein IJ, Mara NA, Wang J, Carpenter JS, Zheng SJ, Han WZ, Zhang RF, Kang K, Nizolek T, Pollock TM. JOM 2012;64:1192.

[11] Beyerlein IJ, Wang J, Zhang RF. Acta Mater 2013;61:7488.

[12] Zhang RF, Germann TC, Liu XY, Wang J, Beyerlein IJ. Scripta Mater 2013;68:114.

[13] Misra A, Hirth JP, Hoagland RG. Acta Mater 2005;53: 4817.

[14] Carpenter JS, Zheng SJ, Zhang RF, Vogel SC, Beyerlein IJ, Mara NA. Philo Mag 2013;93:718. 
[15] Yue YH, Liu P, Deng QS, Ma E, Zhang Z, Han X. NanoLetters 2012;12:4045.

[16] Hunter A, Beyerlein IJ. Appl Phys Lett 2014;104:233112.

[17] Oh SH, Legros M, Kiener D, Gruber P, Dehm G. Acta Mater 2007;55:5558.

[18] Swygenhoven HV, Spaczer M, Caro A. Acta Mater 1999;47:3117.

[19] Asaro RJ, Suresh S. Acta Mater 2005;53:3369.

[20] Traiviratana S, Bringa EM, Benson DJ, Meyers MA. Acta Mater 2008;56:3874.

[21] Hunter A, Beyerlein IJ. Appl Phys Lett Mater 2013;1:032109.

[22] Germann TC. "Large-scale classical molecular dynamics simulations of shock-induced plasticity in BCC niobium," in Shock Compression of Condensed Matter - 2009, M. L. Elert, W. T. Buttler, M. D. Furnish, W. W. Anderson, and W. G. Proud, WG, eds. (AIP Conference Proceedings Vol. 1195, Melville, NY), pp. 761-764.

[23] Zhang RF, Wang J, Beyerlein IJ, Germann TC. Phil Mag Lett 2011;91:731.

[24] Voter AF, Chen SP. Mat Res Soc Symp Proc 1987;82:17.

[25] Ackland GJ, Thetford R. Philos Mag A 1987;56:15.

[26] Demkowicz MJ, Hoagland RG. Inter J Appl Mech 2009;1:421.

[27] Lide DR, CRC Handbook of Chemistry and Physics: A ready-reference Book of Chemical and Physical Data, CRC Press, Boca Raton, FL (2004).

[28] Li JH, Dai Y, Dai XD, Wang TL, Liu BX. Comp Mater Sci 2008;43:1207.

[29] Kaufman L. CALPHAD 1978;2:117.

[30] Yu-Zhang K, Embury JD, Han K, Misra A Philo Mag 2008;88:2559.

[31] Lee SB, LeDonne JE, Lim SCV, Beyerlein IJ, Rollett AD. Acta Mater 2012;60:1747.

[32] Wang J, Hoagland RG, Hirth JP, Misra A. Acta Mater 2008:56:3109.

[33] Wang J, Zhang RF, Zhou CZ, Beyerlein IJ, Misra A. Inter J Plasticity 2014;53:40.

[34] Holian BL, Hoover WG, Moran B, Straub GK. Phys Rev A 1980;22:2498.

[35] Holian BL. Phys Rev A 1988;37:2562.

[36] Holian BL, Lomdahl PS. Science 1998;280:2085. 
[37] Germann TC, Holian BL, Lomdahl PS, Ravelo R. Phys Rev Lett 2000;84:5351.

[38] Ravelo R, Germann TC, Guerrero O, An Q, Holian BL. Phys Rev B 2013;88:134101.

[39] Kadau K, Germann TC, Lomdahl PS, Holian BL. Science 2002;296:1681.

[40] Kadau K, Germann TC, Lomdahl PS, Holian BL. Phys Rev B 2005;72:064120.

[41] Kadau K, Germann TC, Lomdahl PS. Int J Mod Phys C 2004;15:193.

[42] Kelchner CL, Plimpton SJ, Hamilton JC. Phys Rev B 1998;58:11085.

[43] Demkowicz MJ, Wang J, Hoagland RG. in Dislocations in Solids, edited by J. P. Hirth (Elsevier/North-Holland, Amsterdam, 2008), Vol. 14, Chap. 83, p. 141.

[44] Hoagland RG, Hirth JP, Misra A. Philos Mag 2006; 86:3537.

[45] Demkowicz MJ, Hoagland RG, Hirth JP. Phys Rev Lett 2008;100:136102.

[46] Wang J, Zhang RF, Zhou C, Beyerlein IJ, Misra A. J Mater Res 2013;28:1646.

[47] Zhang RF, Wang J, Beyerlein IJ, Misra A, Germann TC. Acta Mater 2012;60:2855.

[48] Zhang RF, Wang J, Beyerlein IJ, Germann TC. Scripta Mater 2011;65:1022.

[49] Misra A, Verdier A, Lu YC, Kung H, Mitchell TE, Nastasi M, et. al. Scripta Mater 1998; $39: 555$

[50] Beyerlein IJ, Mara NA, Carpenter JS, Nizolek T, Mook WA, Wynn T, McCabe RJ, Mayeur JR, Kang K, Zheng SJ, Wang J, Pollock TM. J Mater Res 2013;28:1799.

[51] Werner E, Prantl W. Acta Metall Mater 1990;38:533.

[52] Hoagland RG, Kuntz RJ, Henager CH. Scripta Mater 2004;50:775.

[53] Cao B, Bringa E, Meyers M. Metall Mater Trans A 2007;38:2681.

[54] Meyers MA, Jarmakani H, Bringa EM, Remington BA. in Dislocations in Solids, edited by J. P. Hirth (Elsevier/North-Holland, Amsterdam, 2009), Vol. 15, Chap. 89, p. 91.

[55] Han WZ, Cerreta EK, Mara NA, Beyerlein IJ, Misra A. Acta Mater 2013;63:150. 
TABLE I. The fitted properties of the newly constructed $\mathrm{Cu} / \mathrm{Nb}$ cross potential. These are compared with values from experiment, previous $\mathrm{Cu}-\mathrm{Nb}$ potentials, and ab initio DFT. The lattice parameter a is given in $\AA$, the cohesive energy $\mathrm{E}_{\mathrm{c}}$ in $\mathrm{eV}$, dilute heats of mixing in $\mathrm{eV}$, and the interfacial energy in $\mathrm{mJ} / \mathrm{m}^{2}$. KS indicate Kurdjumov-Sachs fcc/bcc interfaces.

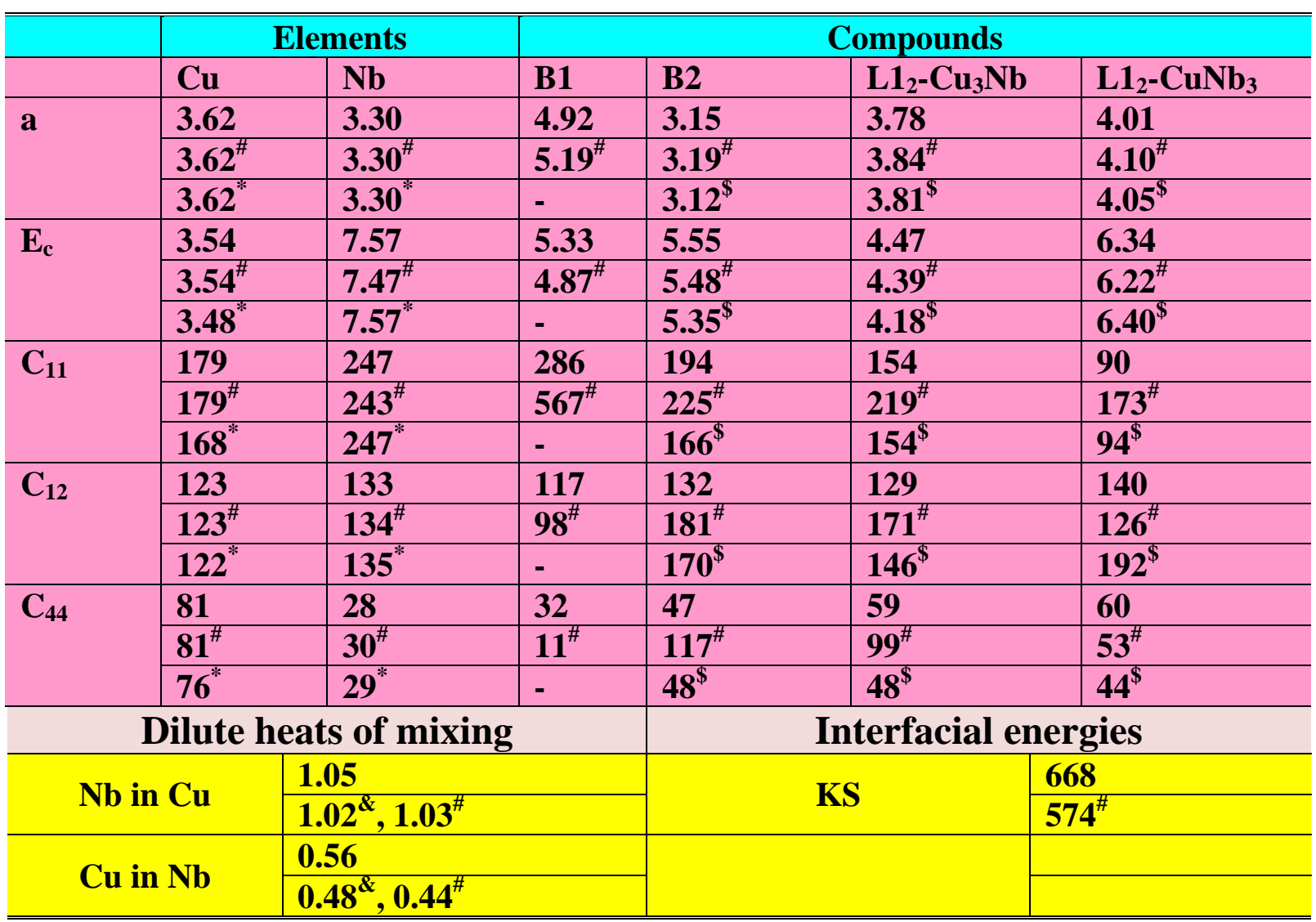

* The experimental data are from Ref. [27]

${ }^{\$}$ The ab initio DFT values from [28]

${ }^{\&}$ Derived from phase diagram thermodynamic calculations [29]

\# The calculated values by the previous $\mathrm{Cu}-\mathrm{Nb}$ potentials by Demkowicz et al. [26] 


\section{Figure Captions}

FIG. 1 (color online). The atomic structure of the $\mathrm{Cu} / \mathrm{Nb}$ interface with the $\mathrm{KS}$ orientation relationship after NPT and quenching relaxation (a) top view from the $\mathrm{Cu}$ side and (b) bottom view from the $\mathrm{Nb}$ side. The interfacial MDIs are indicated by magenta and red color. (c) Twodimensional representation of the unfolded tetrahedron of slip systems out of the interface in the $\mathrm{Cu}$ side, in which the three gliding planes are indicated by the $\mathrm{BCD}, \mathrm{ACD}$, and $\mathrm{ABD}$ planes, and the $\mathrm{ABC}$ plane is the $\mathrm{Cu} / \mathrm{Nb}$ interface. (d) Two-dimensional representation of an unfolded polyhedron of slip systems out of the interface in the $\mathrm{Nb}$ side, in which the five relevant gliding planes are indicated by B'C'F', A'C'G, ACG', A'B'E, A'B'E' planes, and the $\mathrm{Cu} / \mathrm{Nb}$ interface is located at the A'B'C' plane. The interface normal is $[111]_{\mathrm{Cu}} /[110]_{\mathrm{Nb}}$, and the in-plane axes are $[11-2]_{\mathrm{Cu}} / /[1-12]_{\mathrm{Nb}}$ and $[1-10]_{\mathrm{Cu}} / /[-111]_{\mathrm{Nb}}$.

FIG. 2 (color online). Snapshots of (a) Cu2.5nm/Nb2.5nm, (b) Cu5nm/Nb5nm, (c) $\mathrm{Cu} 10 \mathrm{~nm} / \mathrm{Nb} 10 \mathrm{~nm}$, (d) $\mathrm{Cu} 20 \mathrm{~nm} / \mathrm{Nb} 20 \mathrm{~nm}$ multilayer models and (e) bulk $\mathrm{Nb}$ taken at nearly the Hugniot elastic limit (HEL). The atoms are colored by common neighbor analysis (CNA). Note that the partial dislocations are emitted from the interfaces into the $\mathrm{Cu}$ layers for (a), (b) and (c), while into the $\mathrm{Nb}$ layers for (d) and (e).

FIG. 3 (color online). Snapshots of (a) $\mathrm{Cu} 2.5 \mathrm{~nm} / \mathrm{Nb} 2.5 \mathrm{~nm}$, (b) $\mathrm{Cu} 5 \mathrm{~nm} / \mathrm{Nb} 5 \mathrm{~nm}$, (c) $\mathrm{Cu} 10 \mathrm{~nm} / \mathrm{Nb} 10 \mathrm{~nm}$, (d) $\mathrm{Cu} 20 \mathrm{~nm} / \mathrm{Nb} 20 \mathrm{~nm}$ multilayers with a KS orientation relationship at time $=19.5 \mathrm{ps}$ (near the end of shock compression). In each panel, the sample is travelling at a particle velocity $u_{p}=650 \mathrm{~m} / \mathrm{s}$. The atoms are colored according to their common neighbor analysis (CNA). The deformation in $\mathrm{Cu}$ is mediated by Shockley partials and in $\mathrm{Nb}$ by $\{110\}<111>$ slip.

FIG. 4 (color online). a) Side view and b) top view of dislocation nucleation from a misfit dislocation lines within the interface into the $\mathrm{Cu}$ crystal at timestep $=6.5 \mathrm{ps}$ and $\mathrm{c}$ ) side view and d) top view of the dislocation transmission from the $\mathrm{Cu}$ side into the $\mathrm{Nb}$ side at the timestep of 7ps, along the misfit dislocation line. The sample is travelling upward at a particle velocity $u_{\mathrm{p}}=650 \mathrm{~m} / \mathrm{s}$ towards a stationary piston at the top, which specularly reflects any particles that reach it; a resulting shockwave travels downward.

FIG. 5 (color online). Schematic showing slip system transmission from a top layer/grain into the adjacent bottom layer/grain. The slip plane normal of the top and bottom layers are $n$ and 
$\mathrm{n}$ ', respectively and the Burgers vectors are $\mathrm{b}$ and b', respectively. The geometric compatibility factor is defined as $\mathrm{m}^{\prime}=\cos \varphi \cos \lambda$, where $\varphi$ is the angle between the slip direction, i.e. angle(b,b'), and $\lambda$ is the angle between the normal to the slip planes, i.e. angle $\left(n, n^{\prime}\right)$.

FIG. 6 (color online). (a) Orientation of the fcc and bcc gliding planes with respect to the KS interface to indicate the most probable transmission pathway. (b) Top view of the atomic structure from the $\mathrm{Cu}$ side together with the traces of the gliding planes at the interface, black $\mathrm{ABC}^{\prime}$ is for the $\mathrm{Nb}$ side, pink $\mathrm{ABC}$ for the $\mathrm{Cu}$ side. The interface normal is assigned as $[111]_{\mathrm{Cu}} / /[110]_{\mathrm{Nb}}$ with $[11-2]_{\mathrm{Cu}} / /[1-12]_{\mathrm{Nb}}$ and $[1-10]_{\mathrm{Cu}} / /[-111]_{\mathrm{Nb}}$. The transmission paths from $\mathrm{Cu}$ to $\mathrm{Nb}$ (or from $\mathrm{Nb}$ to $\mathrm{Cu}$ ) are $\mathrm{ABD}_{\mathrm{Cu}^{-}}>\mathrm{A}^{\prime} \mathrm{B}^{\prime} \mathrm{E}^{\prime} \mathrm{Nb}, \mathrm{BCD}_{\mathrm{Cu}^{-}}>\mathrm{B}^{\prime} \mathrm{C}^{\prime} \mathrm{F}^{\prime}{ }_{\mathrm{Nb}}, \mathrm{ACD}_{\mathrm{Cu}^{-}}>$ $\mathrm{A}^{\prime} \mathrm{C}^{\prime} \mathrm{G}^{\prime}{ }_{\mathrm{Nb}}$. The possible slip systems are shown in Fig. 1c and $1 \mathrm{~d}$.

FIG. 7 (color online). a) Side view and b) bottom view of dislocation transmission from $\mathrm{Cu}$ into $\mathrm{Nb}$ at $8 \mathrm{ps}$ and c) side view and d) top view of dislocation transmission from $\mathrm{Nb}$ into $\mathrm{Cu}$ at $8.5 \mathrm{ps}$. The sample is travelling upward at a particle velocity $\mu_{p}=650 \mathrm{~m} / \mathrm{s}$ towards a stationary piston at the top, which specularly reflects any particles that reach it; a resulting shockwave travels downward.

FIG. 8 (color online). The change in the atomic structure of the $\mathrm{Cu} / \mathrm{Nb}$ interface during dislocation transmission from the $\mathrm{Cu}$ side to the $\mathrm{Nb}$ side at a timestep of 8 ps (see Fig. 3a) (a) top view from $\mathrm{Cu}$ side and (b) bottom view from $\mathrm{Nb}$ side. The interface normal is $[111]_{\mathrm{Cu}} / /[110]_{\mathrm{Nb}}$.

FIG. 9 (color online). Change in atomic percent of the central symmetry factor (CSF) for values of $\mathrm{CSF}$ greater than unity for the $\mathrm{Cu} 5 \mathrm{~nm} / \mathrm{Nb} 5 \mathrm{~nm}$ multilayer model. The annealing times indicate dislocation recovery processes upon shock release. 

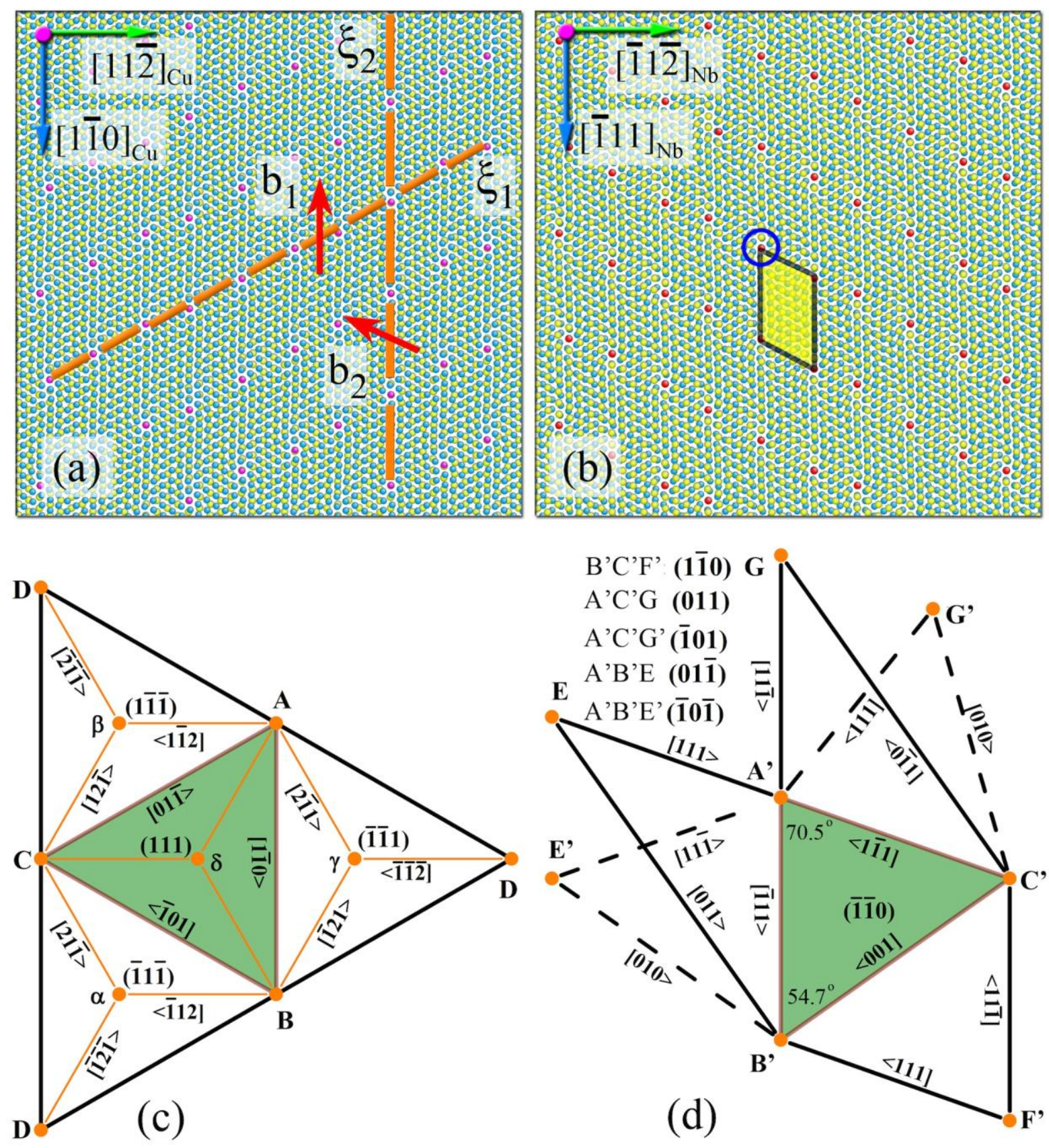


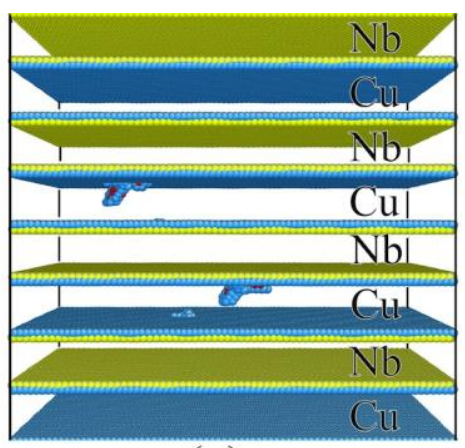

(a)

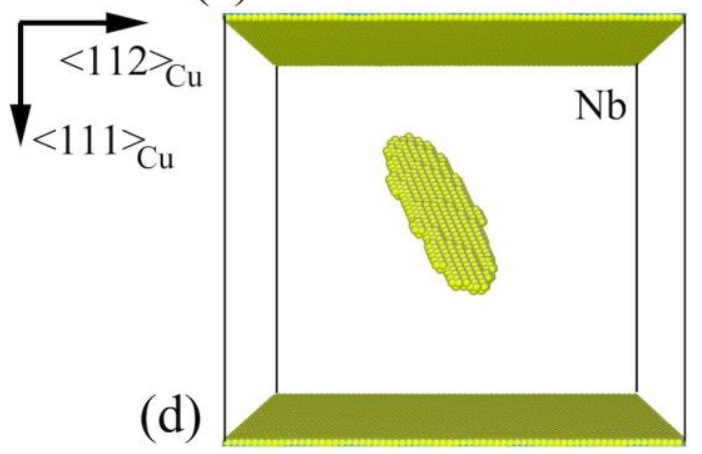

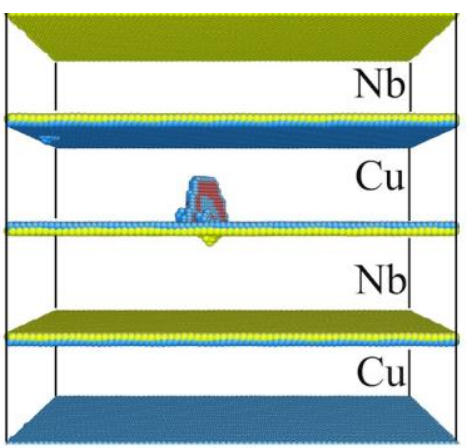

(b)

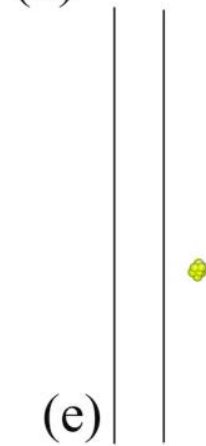

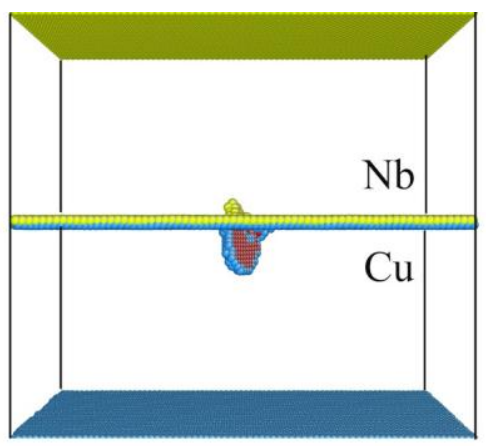

(c)

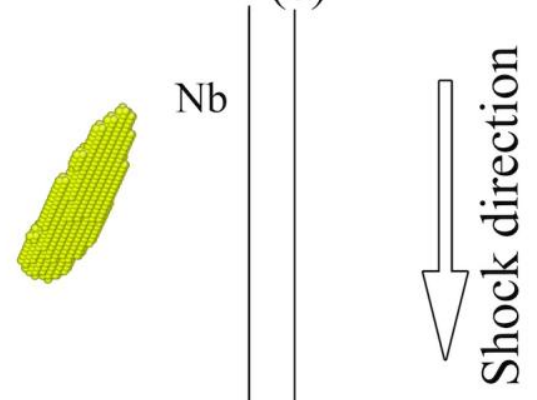


(a)
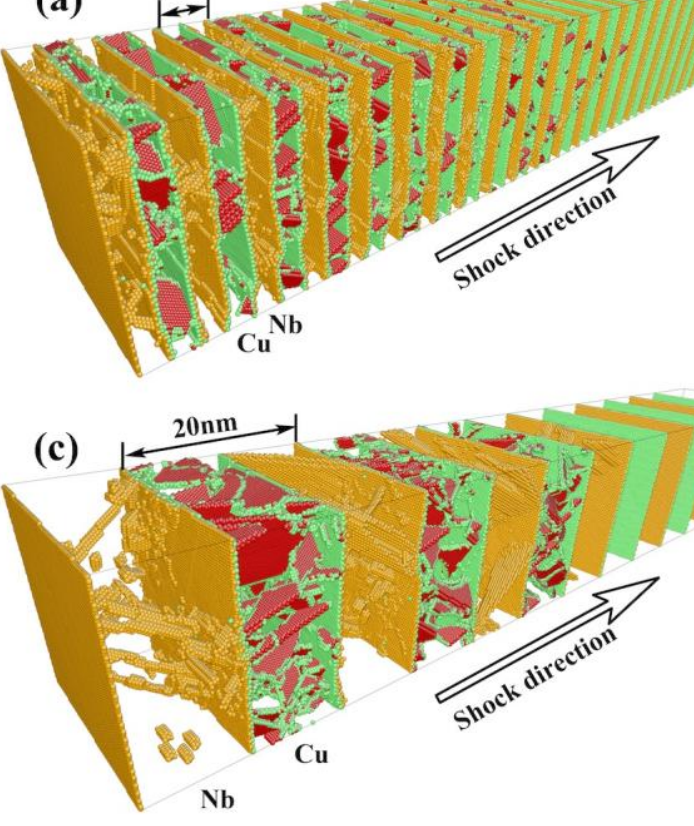
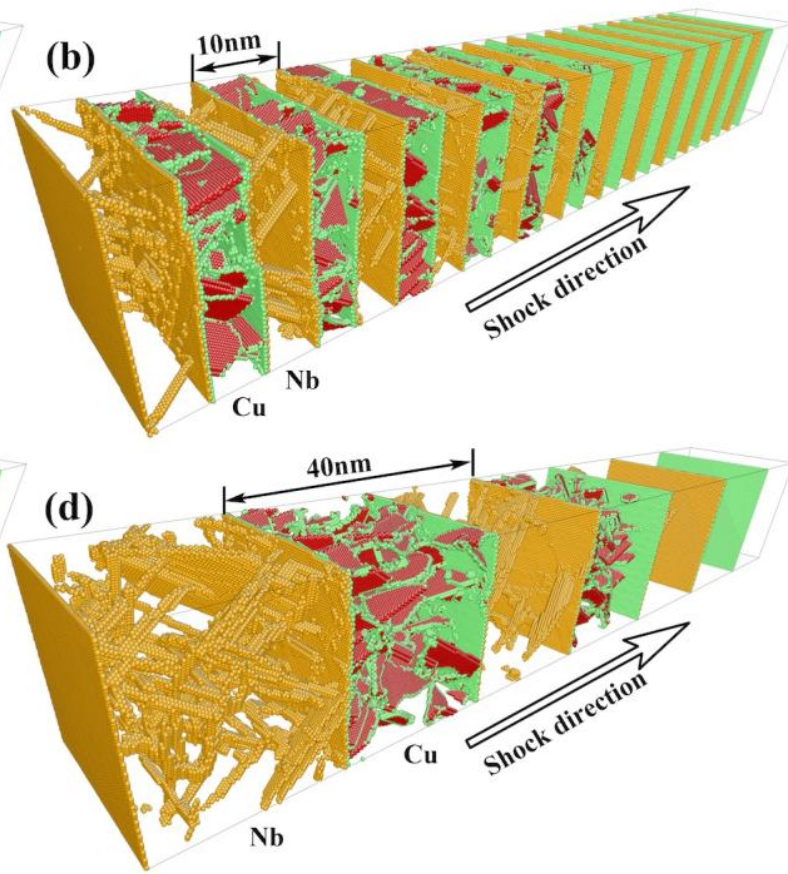

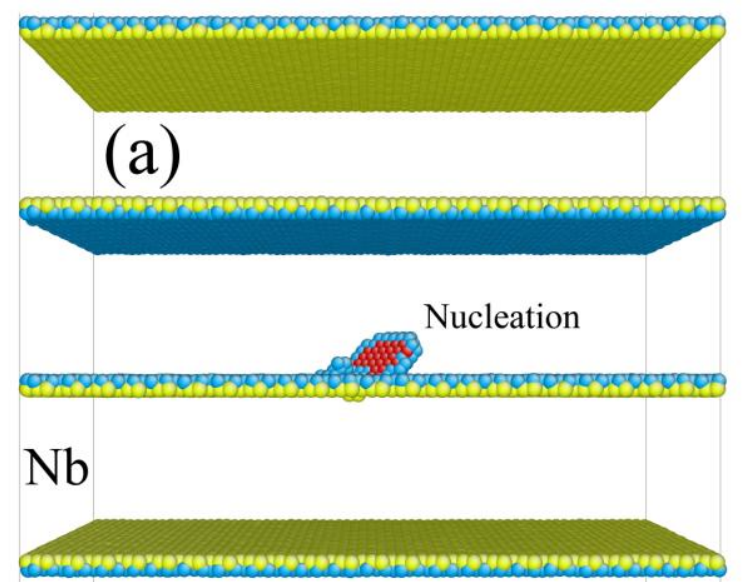

\section{$\mathrm{Cu}$}
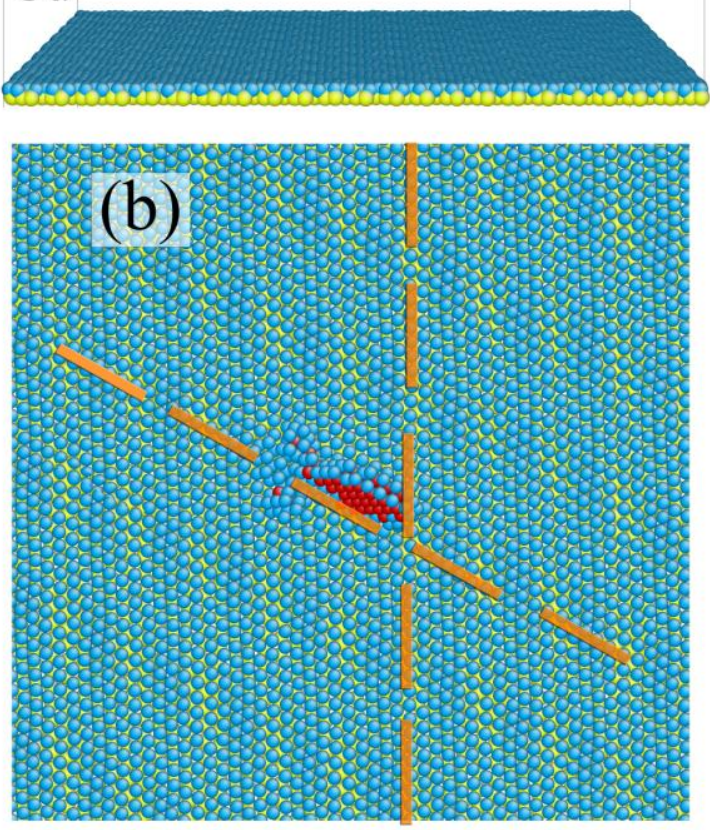
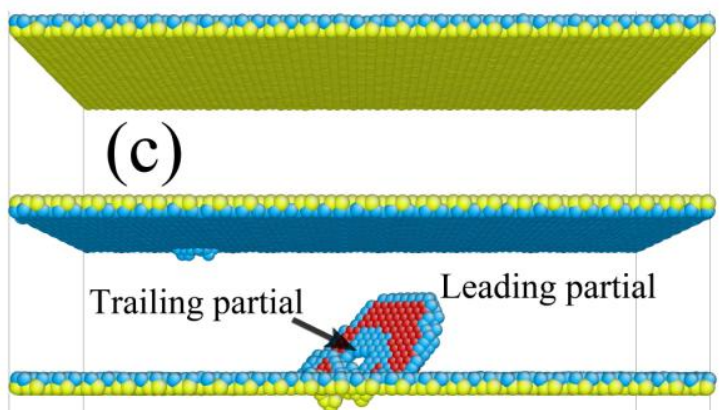

$\mathrm{Nb}$
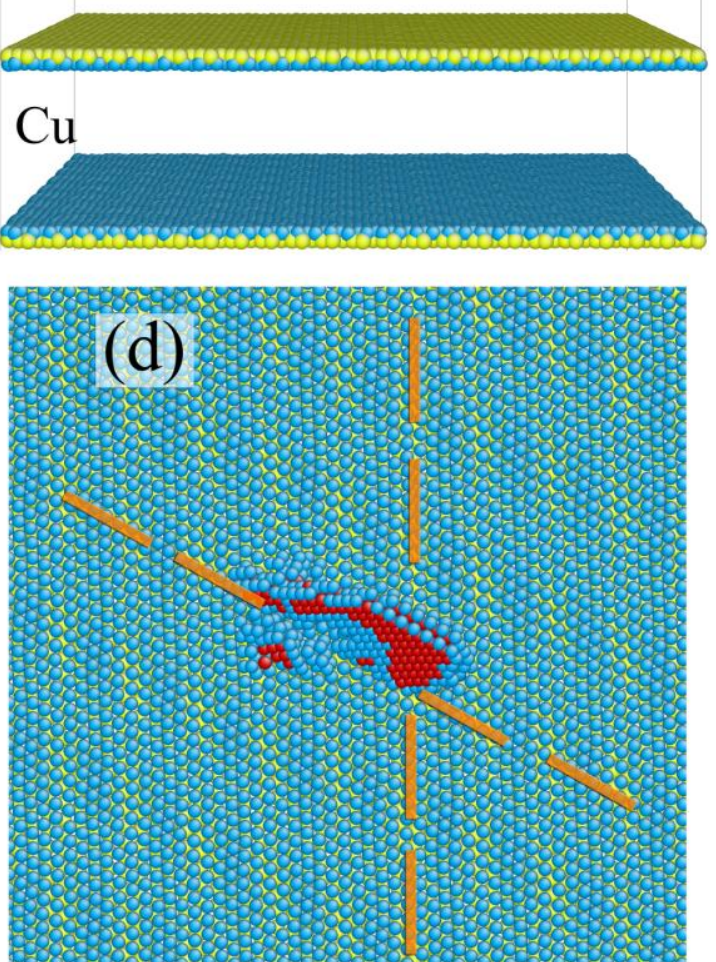


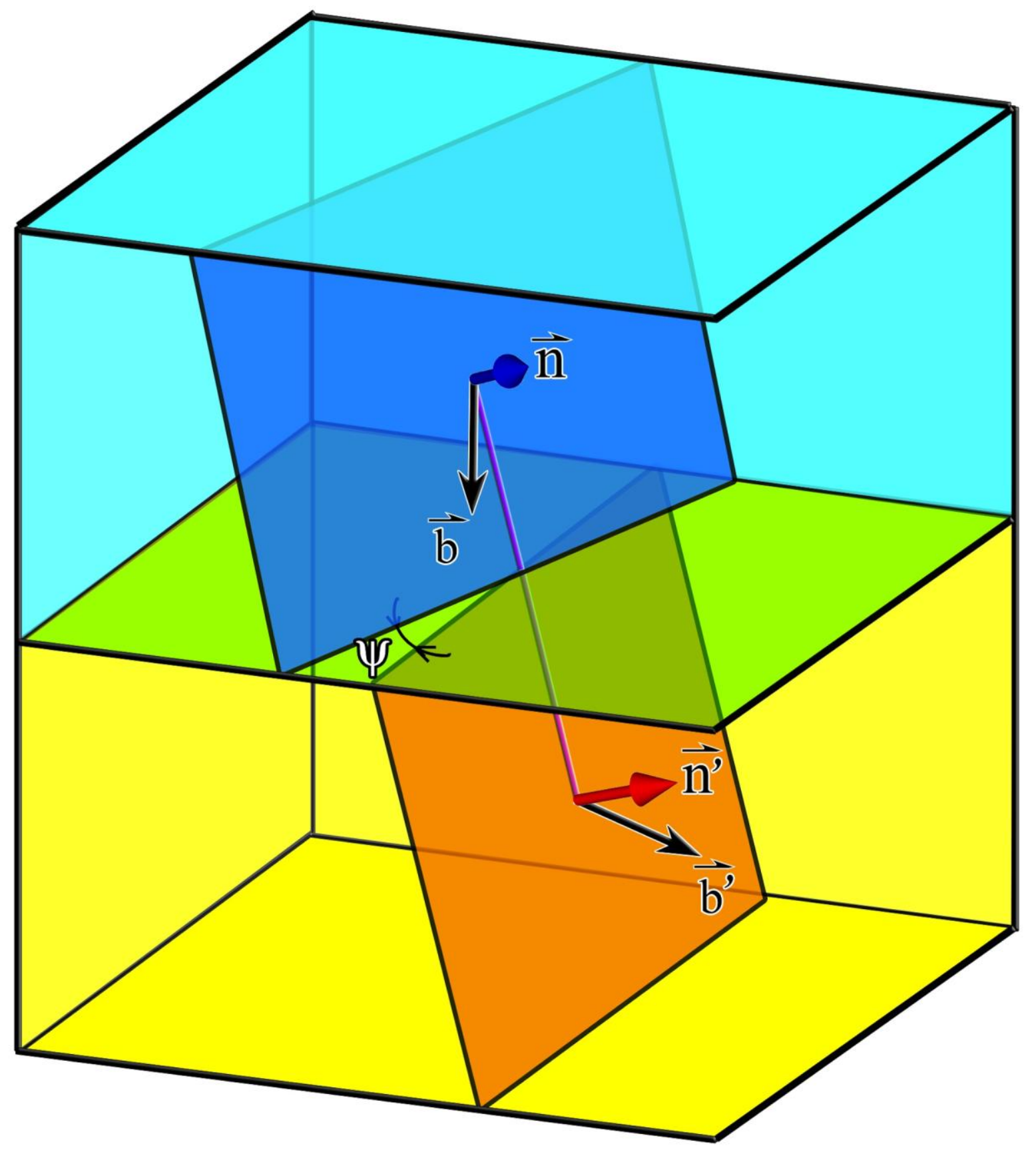



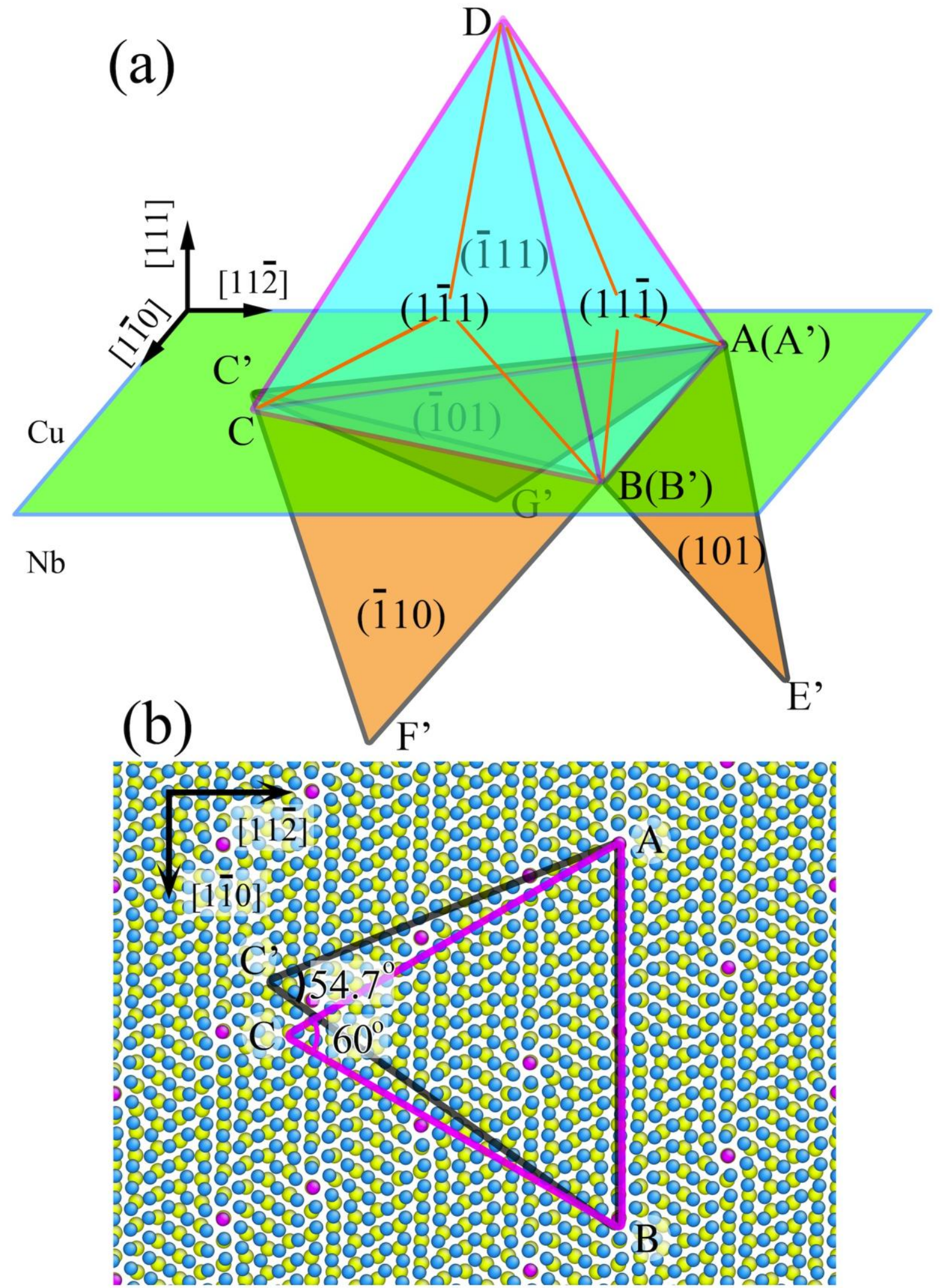

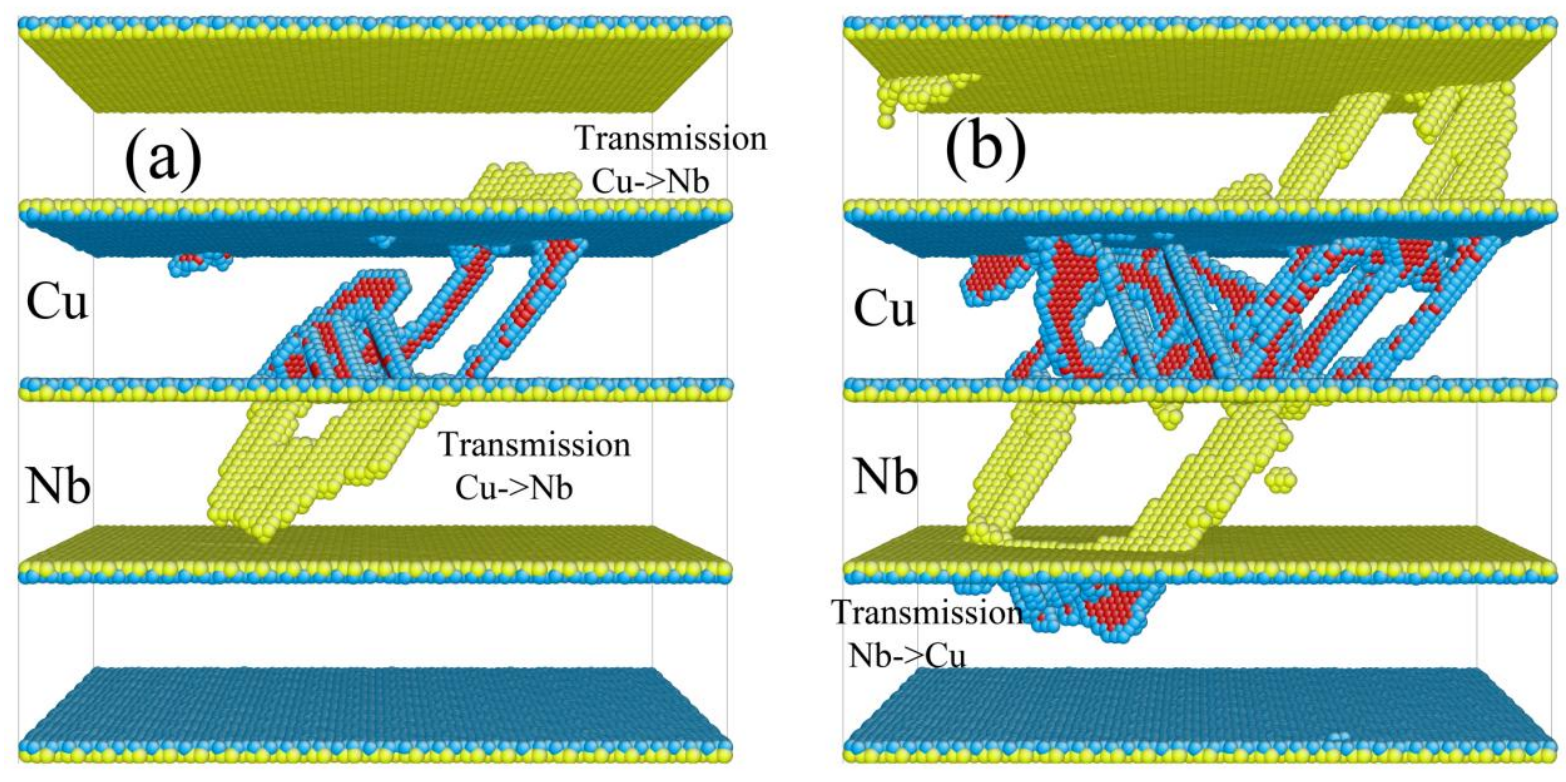

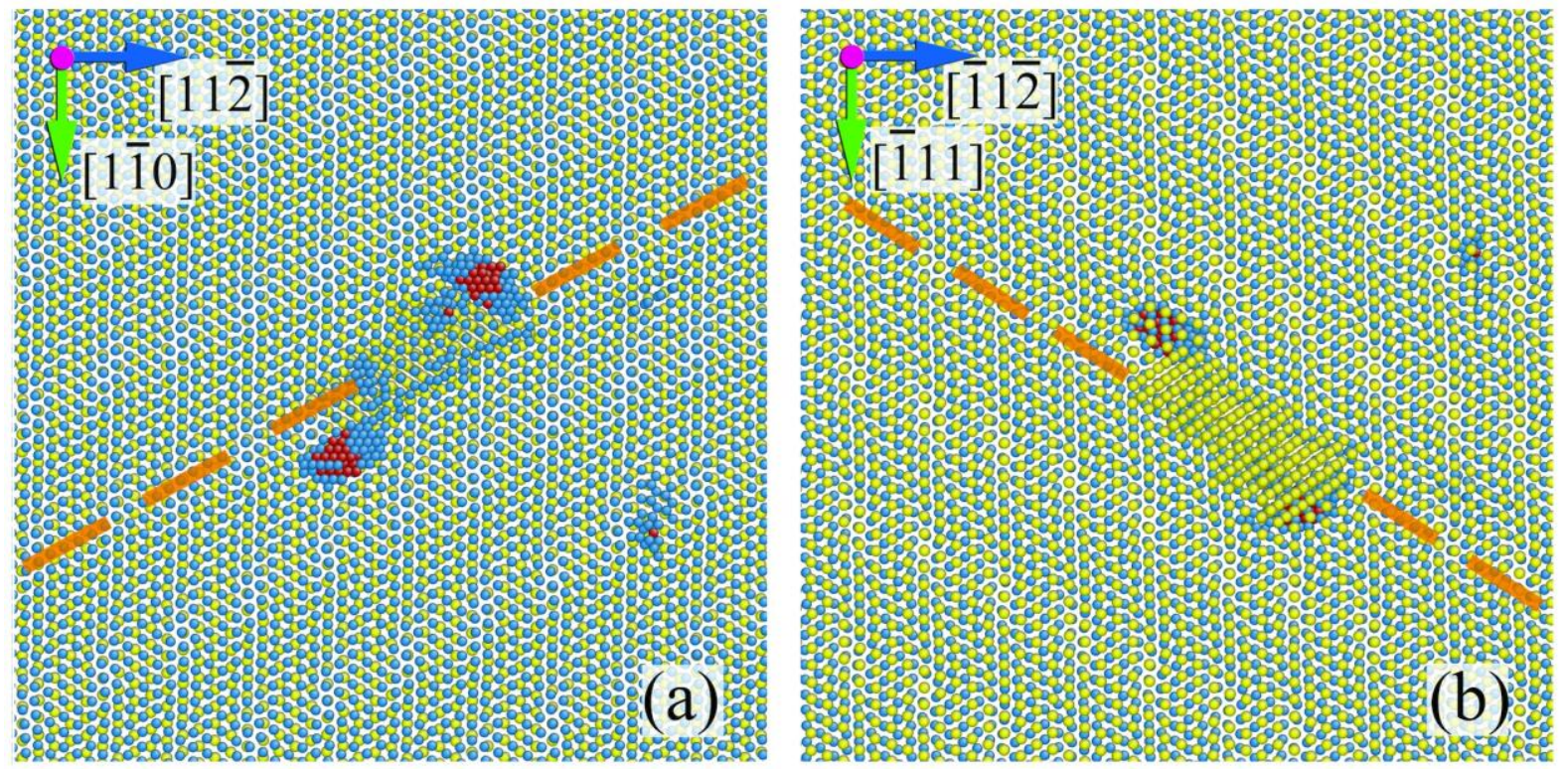


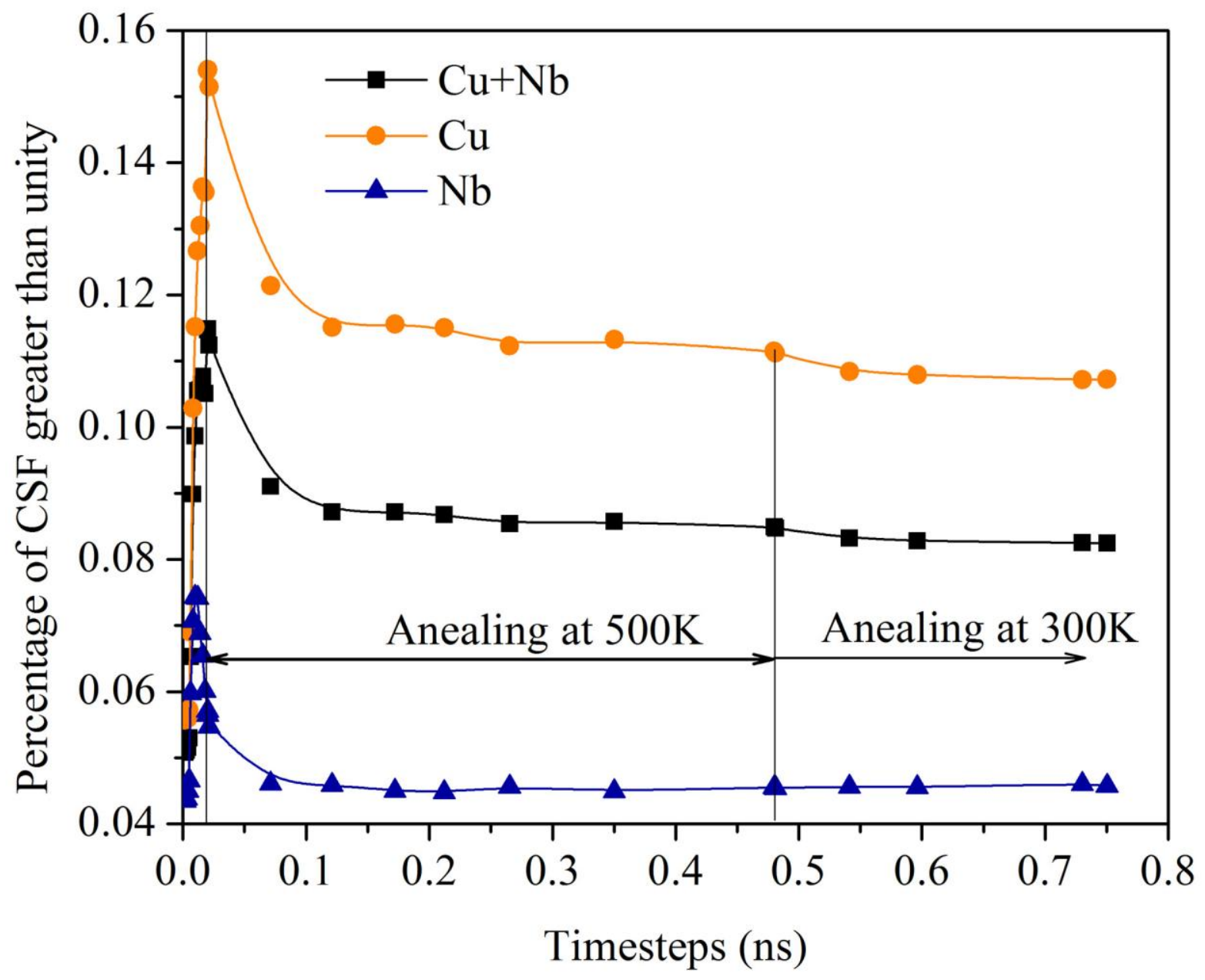

